\title{
Selected SALM (Synaptic Adhesion-Like Molecule) Family Proteins Regulate Synapse Formation
}

\author{
Won Mah, ${ }^{*}$ Jaewon Ko, ${ }^{\star}$ Jungyong Nam, ${ }^{*}$ Kihoon Han, Woo Suk Chung, and Eunjoon Kim \\ National Creative Research Initiative Center for Synaptogenesis, Department of Biological Sciences, and Department of Nanoscience and Technology, \\ KAIST, Daejeon 305-701, Korea
}

Synaptic cell adhesion molecules regulate various steps of synapse formation. Despite the great diversity of neuronal synapses, relatively few adhesion molecules with synaptogenic activity have been identified. Synaptic adhesion-like molecules (SALMs) are members of a family of cell adhesion molecules known to regulate neurite outgrowth and synapse maturation; however, the role of SALMs in synapse formation remains unknown. We found that expression of the SALM family proteins SALM3 and SALM5 in nonneural and neural cells induces both excitatory and inhibitory presynaptic differentiation in contacting axons. SALM3 and SALM5 proteins are enriched in synaptic fractions, and form strong (SALM3) or weak (SALM5) complexes with postsynaptic density-95 (PSD-95), an abundant postsynaptic scaffolding protein at excitatory synapses. Aggregation of SALM3, but not SALM5, on dendritic surfaces induces clustering of PSD-95. Knockdown of SALM5 reduces the number and function of excitatory and inhibitory synapses. These results suggest that selected SALM family proteins regulate synapse formation, and that SALM3 and SALM5 may promote synapse formation through distinct mechanisms.

\section{Introduction}

Various cellular and molecular processes regulate events involved in neuronal synapse development, including interactions between dendrites and axons, and formation and maturation of early synapses. Synaptic cell adhesion molecules play important roles in the regulation of these processes (Li and Sheng, 2003; Scheiffele, 2003; Yamagata et al., 2003; Washbourne et al., 2004; Levinson and El-Husseini, 2005; Akins and Biederer, 2006; Dean and Dresbach, 2006; Craig and Kang, 2007; Dalva et al., 2007; Han and Kim, 2008; Südhof, 2008; Brose, 2009; Giagtzoglou et al., 2009; Togashi et al., 2009; Woo et al., 2009a).

Synaptic adhesion-like molecules (SALMs; also known as Lrfns), are members of a family of synaptic adhesion molecules consisting of five known members: SALM1/Lrfn2, SALM2/Lrfn1, SALM3/Lrfn4, SALM4/Lrfn3, and SALM5/Lrfn5 (Ko et al., 2006; Morimura et al., 2006; Wang et al., 2006; Ko and Kim, 2007). SALMs contain six leucine-rich repeats (LRRs) flanked by $\mathrm{N}$-terminal (LRRNT) and C-terminal (LRRCT) domains, an Ig domain and a fibronectin III (FNIII) domain in the extracellular region, followed by a single transmembrane domain and an intracellular region that ends with a C-terminal PDZ-binding motif. The intracellular regions of SALMs differ in their length and

Received Sept. 29, 2009; revised Jan. 3, 2010; accepted March 16, 2010.

This work was supported by the Creative Research Initiative Program of the Korean Ministry of Education, Science and Technology (to E.K.). We thank Dr. Robert J. Wenthold (National Institutes of Health) for the kind gift of the SALM4-Myc expression construct and Daeun Kim and Yangkyun Oh for help with SALM3/5 antibody generation.

${ }^{*}$ W.M., J.K., and J.N. contributed equally to this work.

Correspondence should be addressed to Eunjoon Kim, Department of Biological Sciences, KAIST, Kuseongdong, Yuseong-ku, Daejeon 205-701, Korea. E-mail: kime@kaist.ac.kr.

J. Ko's present address: Stanford University School of Medicine, Neuroscience Institute, 1050 Arastradero Road, Palo Alto, CA 94304

DOI:10.1523/JNEUROSCI.4839-09.2010

Copyright $\odot 2010$ the authors $\quad 0270-6474 / 10 / 305559-10 \$ 15.00 / 0$ share essentially no amino acid sequence identity. Furthermore, SALM4 and SALM5, unlike SALM1, SALM2, and SALM3, do not possess the C-terminal PDZ-binding motif, suggesting that different SALMs may have distinct functions. mRNAs of SALMs are mainly expressed in the brain and various brain regions, as determined by Northern and in situ hybridization analyses (Ko et al., 2006; Morimura et al., 2006).

SALM1, SALM2, and SALM3 interact with postsynaptic density-95 (PSD-95) in vitro via their PDZ-binding $\mathrm{C}$ termini (Ko et al., 2006; Morimura et al., 2006; Wang et al., 2006), and SALM1 and SALM2 have been shown to form a complex with PSD-95 in vivo (Ko et al., 2006; Wang et al., 2006). SALM1 directly interacts with the NR1 subunit of NMDA receptors, but not with AMPA receptors, and promotes surface expression and dendritic clustering of NMDA receptors in cultured neurons (Wang et al., 2006). SALM1 also regulates neurite outgrowth in early-stage neurons (Wang et al., 2006). SALM2 associates with both NMDA and AMPA receptors and regulates the maturation of excitatory synapses (Ko et al., 2006). Recently, all five SALM family proteins were found to regulate neurite outgrowth (Wang et al., 2008). In addition, SALM1, SALM2, and SALM3 form a coimmunoprecipitable complex, and SALM4 and SALM5 mediate homophilic and transcellular adhesions (Seabold et al., 2008). Although SALMs are involved in neurite outgrowth and synapse maturation, their function in synapse formation remains unknown.

Here we demonstrate that SALM3 and SALM5, but not other members of the SALM family, are capable of inducing excitatory and inhibitory presynaptic differentiation in contacting axons. SALM3 and SALM5 proteins are enriched at synapses, and form a complex with PSD-95. Aggregation of SALM3, but not SALM5, on dendrites promotes PSD-95 clustering. Knockdown of SALM5 
decreases the number and function of excitatory and inhibitory synapses. These results suggest that selected members of the SALM family regulate excitatory and inhibitory synapse formation through distinct mechanisms.

\section{Materials and Methods}

cDNA constructs. Full-length human SALM1 (aa 1-788), rat SALM2 (aa 1-766), mouse SALM3 (aa 1-636), mouse SALM4 (aa 1-626), and mouse SALM5 (aa 1-719) were subcloned into pEGFP-N1 vector (Clontech). For untagged SALM3 and SALM5, fulllength mouse SALM3 (aa 1-636) and mouse SALM5 (aa 1-719) were subcloned into pGW1vector, respectively (British Biotechnology). For N-terminally ECFP-tagged SALM3, ECFP was inserted between aa 16 and 17 of mouse SALM3, For N-terminally EGFP-tagged SALM5, EGFP was inserted between aa 19 and 20 of mouse SALM5. For C-terminal Myctagged SALM constructs, full-length human SALM1 (aa 1-788), rat SALM2 (aa 1-766), mouse SALM3 (aa 1-636), and rat/mouse SALM5 (aa 1-719) were subcloned into pcDNA3.1 Myc HisA vector (Invitrogen). Extracellular regions of SALMs were subcloned into pDisplay vector (Invitrogen): SALM1 (aa 21-532), SALM2 (aa 34-534), SALM3 (aa 17516), SALM4 (aa 28-526), and SALM5 (aa 20511). The SALM4-Myc was a kind gift from Dr. Robert Wenthold. For shRNA SALM5 knockdown constructs, nucleotides 1454-1472 of rat SALM5 (GTG TCT TGG CCA TAT ATG A), and its point mutant (GTG TAT TGG CGA TCT ACG A), were subcloned into pSuper.gfp/ neo vector (OligoEngine). For SALM5 rescue experiments, mouse SALM5 (aa 1-719) was subcloned into pIRES2-EGFP vector (Clontech). The EGFP-NGL-3 and EGFP-Ecto constructs have been described (Kim et al., 2006; Woo et al., 2009b).

Antibodies. SALM3 (1816) guinea pig polyclonal antibody and SALM3 (1828) and SALM5 (1907) rabbit polyclonal antibodies were generated using synthetic peptides (aa 594-608 of rat SALM3, CYGYARRLGGAWARR, and aa 707-719 of rat SALM5, CDQNVQETQRLESI), respectively. SALM5 guinea pig polyclonal antibodies (1911) were generated using $\mathrm{H}_{6}$-SALM5 (aa 551-719). SulfoLink column (Pierce) was used for affinity purification of the antibodies. The following antibodies have been described previously: SALM2 (1348) (Ko et al., 2006), PSD-95 (1402) (Choi et al., 2005), Shank (3856) (Choi et al., 2005), CASK (1640) (Kim et al., 2009), NGL (1583) (Kim et al., 2006), Piccolo (1203) (Kim et al., 2003), and EGFP (1173) (Ko et al., 2003). The other antibodies were purchased commercially: PSD-95 (Affinity BioReagents), gephyrin, synaptotagmin I lumenal, vGlut1, VGAT (Synaptic Systems), GABA ${ }_{\mathrm{A}}$ receptor $\gamma 2$ (Synaptic Systems), NR1, synapsin I (Millipore Bioscience Research Reagents), Myc, HA (Santa Cruz Biotechnology), synaptophysin, and $\alpha$-tubulin (Sigma).

Mixed-culture assays. Mixed-culture (or coculture) assays were performed as described previously (Scheiffele et al., 2000; Biederer and Scheiffele, 2007). In brief, HEK293T cells were transfected with EGFP-f (farnesylated EGFP; negative control), SALMs-EGFP plasmids, or pDisplay SALMs plasmids (SALMs-Ecto) for $48 \mathrm{~h}$, trypsinized, plated onto cultured hippocampal neurons, cocultured for $3 \mathrm{~d}$ [days in vitro (DIV) 9-12 or 5-8], and immunostained for EGFP, HA, synapsin I, vGlut1, VGAT, Piccolo, synaptophysin, PSD-95, gephyrin, or synaptotagmin I
B

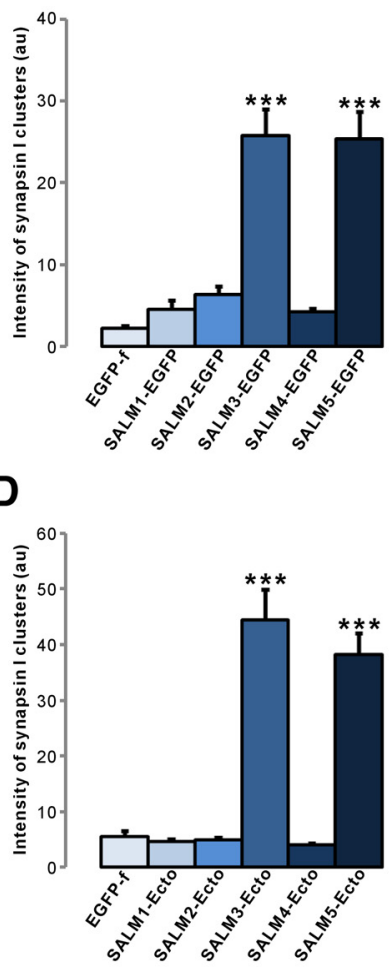

C

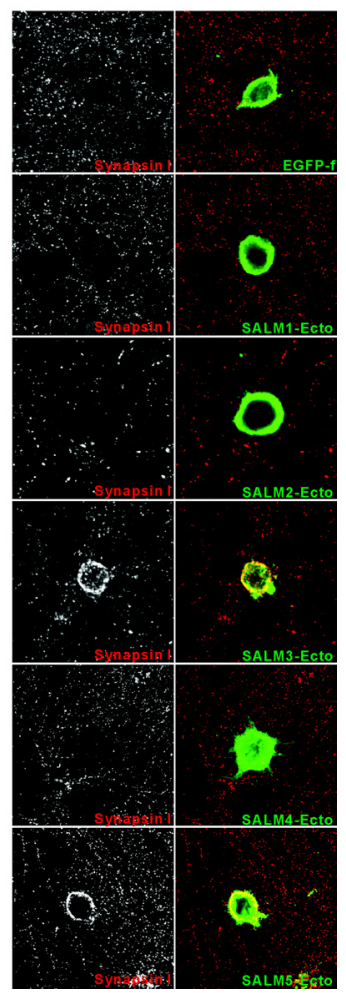

Figure 1. SALM3 and SALM5 expressed in nonneural cells induce presynaptic differentiation in contacting axons. $A, S A L M 3$ and

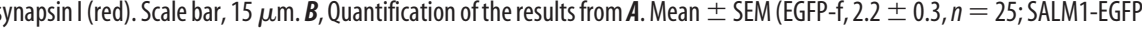
作, and SALM4, induce synapsin I clustering in contacting axons of cocultured neurons. HEK293T cells were transfected $\pm 0.5, n=25 ;$ SALM3-Ecto, $44.5 \pm 5.4, n=29 ;$ SALM4-Ecto, $4.0 \pm 0.3, n=31$; SALM5-Ecto, $38.2 \pm 3.9$ $n=31,{ }^{* * *} p<0.001 ;$ ANOVA, Tukey's test).

(lumenal domain). For synaptotagmin uptake assays, live neurons were incubated with synaptotagmin I lumenal domain antibodies (1:10) in depolarizing solution for $5 \mathrm{~min}$ at $37^{\circ} \mathrm{C}$.

Neuron culture, transfection, and immunocytochemistry. Primary hippocampal cultures were prepared from embryonic day 18 rat hippocampi. Cultured neurons were transfected using Calphos transfection kit (Clontech) and fixed with 4\% paraformaldehyde/4\% sucrose, or $100 \%$ cold methanol, permeabilized with $0.2 \%$ Triton X-100 in phosphate buffered saline, and incubated with specific primary and Cy3-or FITC-conjugated secondary antibodies. The following antibodies were used for immunocytochemistry of cocultured neurons: EGFP (1173, 1:1000), HA ( $1 \mu \mathrm{g} / \mathrm{ml})$, synapsin I (1:2000), vGlut1 (1:500), VGAT (1: 200), synaptophysin (1:200), Piccolo (1203, $1.5 \mu \mathrm{g} / \mathrm{ml})$, PSD-95 (1:500), and gephyrin (1:500).

Image acquisition and quantification. Z-stacked fluorescent images were acquired using a confocal microscope (LSM510; Zeiss). The same parameter settings were kept constant for all scanning. Each experiment was repeated at least three times. To determine the average fluorescent intensity of synaptic protein clusters, randomly chosen HEK293T cells were used for quantification with MetaMorph software (Universal Imaging). Acquired images were thresholded, and the integrated intensity of the clusters on a HEK293T cell was normalized to the cell area. Significance of the quantification was determined by ANOVA, Tukey's test. 
A

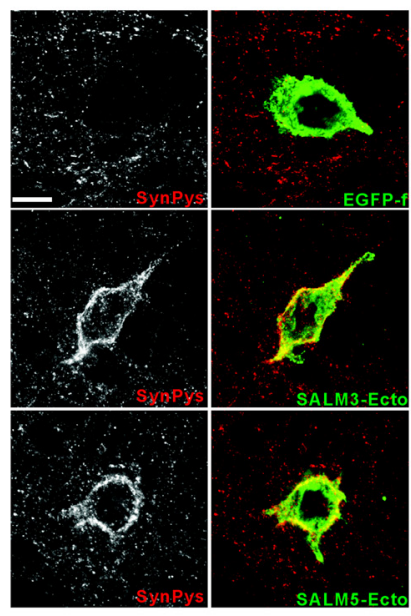

C

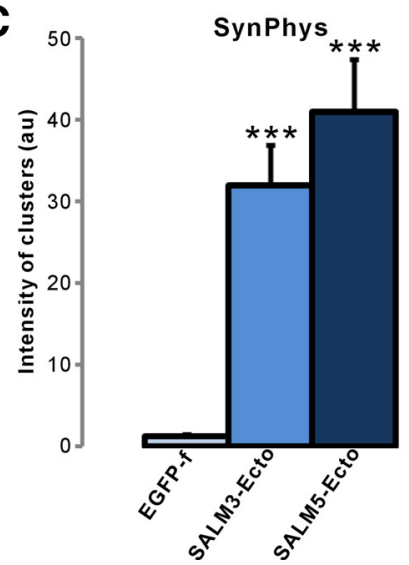

B
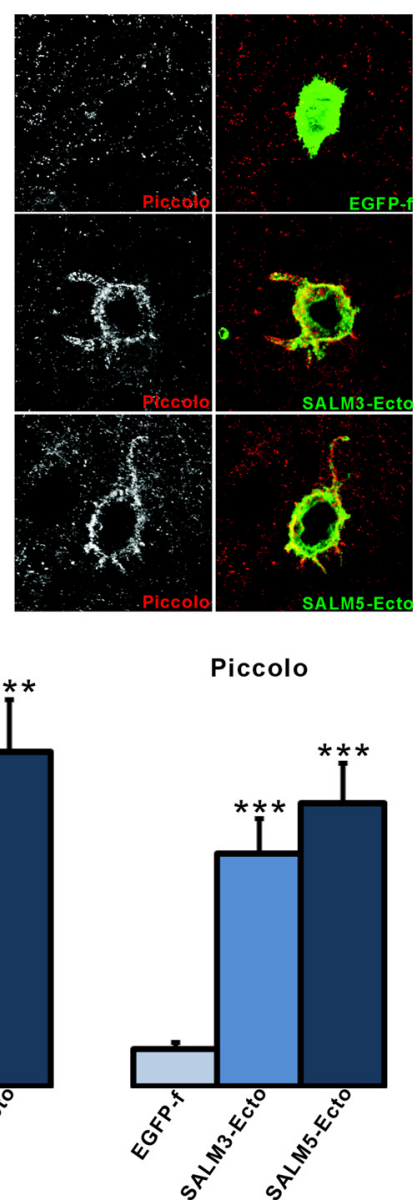

D

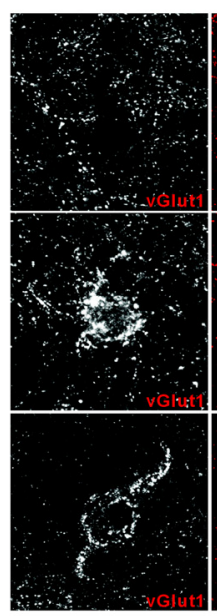

F

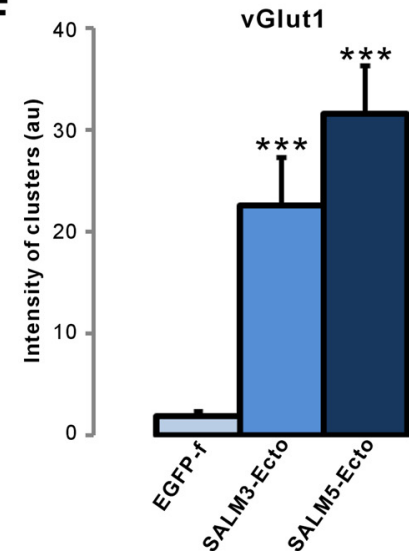

E

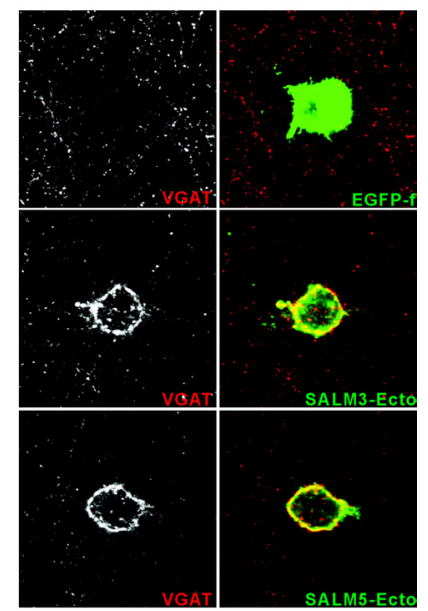

VGAT

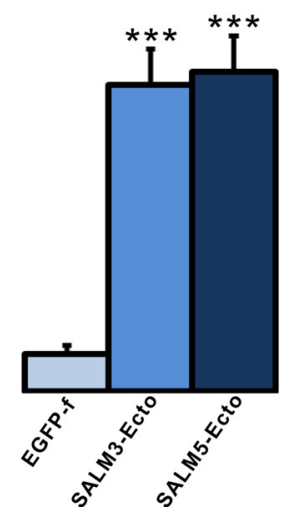

Figure 2. SALM3 and SALM5 induce excitatory and inhibitory presynaptic protein clustering. A, B, SALM3 and SALM5 induce the clustering of synaptophysin and Piccolo in contacting axons of cocultured neurons. HEK293T cells were transfected with SALM3-Ecto, SALM5-Ecto, or EGFP-f, and cocultured with rat hippocampal neurons (DIV 9-12), followed by immunostaining for synaptophysin and Piccolo. Scale bar, $15 \mu \mathrm{m}$. C, Quantification of the results from $\boldsymbol{A}$ and $\boldsymbol{B}$. Mean \pm SEM (Synaptophysin, EGFP-f, $1.3 \pm 0.2, n=19 ;$ SALM3-Ecto, 32.0 $\pm 5.0, n=21$, SALM5-Ecto, $41.0 \pm 6.4, n=19 ;$ Piccolo, EGFP-f, $4.6 \pm 0.8, n=21 ;$ SALM3-Ecto, $28.5 \pm 4.3, n=24 ;$ SALM5-Ecto, $34.7 \pm 5.0, n=18 ;{ }^{* * *} p<0.0001$; ANOVA, Tukey's test). D, E, SALM3 and SALM5 expressed in nonneural cells induce the clustering of both vGlut1 and VGAT (excitatory and inhibitory presynaptic markers, respectively). HEK293T cells were transfected with SALM3-Ecto, SALM5-Ecto, or EGFP-f (control), and cocultured with rat hippocampal neurons (DIV 9-12), followed by immunostaining for vGlut1 (D) or VGAT (E). Scale bar, $15 \mu \mathrm{m}$. $\boldsymbol{F}$, Quantification of the results from $\boldsymbol{D}, \boldsymbol{E}$. Mean \pm SEM (vGlut1, EGFP-f, $1.9 \pm 0.6, n=20 ;$ SALM3-Ecto, $22.6 \pm 4.8, n=28 ;$ SALM5-Ecto, $31.6 \pm 7.2, n=37$; VGAT, EGFP-f, $3.7 \pm 0.9, n=20 ;$ SALM3-EGFP, 30.1 $\pm 3.6, n=35$; SALM5-EGFP, $31.4 \pm 4.3, n=40 ;{ }^{* * *} p<0.0001$; ANOVA, Tukey's test).

Antibody aggregation assays. Antibody incubation assays were performed as described previously (Woo et al., 2009b). Briefly, guinea pig EGFP antibodies were preclustered by FITC-conjugated anti-guinea pig donkey antibodies (Jackson ImmunoResearch Laboratories) in the ratio of 1:3 in complete neurobasal medium (Invitrogen) for $2 \mathrm{~h}$ at $4^{\circ} \mathrm{C}$, followed by incubation with neurons expressing N-terminally ECFP/EGFP-tagged SALM3/5 (DIV 14-15), followed by $24 \mathrm{~h}$ culture and immunofluorescence staining at DIV 16.

Electrophysiology. To measure mEPSCs and mIPSCs, cultured hippocampal pyramidal neurons transfected with sh-SALM5 (DIV 10-14 or 15) were recorded by whole-cell voltage clamp at $-60 \mathrm{mV}$ with Axopatch 200B amplifier (Molecular Devices). The extracellular solution contained the following (in mM): $145 \mathrm{NaCl}, 2.5 \mathrm{KCl}, 10$ HEPES, 1.25 $\mathrm{NaH}_{2} \mathrm{PO}_{4}, 2 \mathrm{CaCl}_{2}, 1 \mathrm{MgCl}_{2}, 10$ glucose, and 0.4 sodium ascorbate. The intracellular solution contained the following (in mM): 100 potassium gluconate, $20 \mathrm{KCl}, 10 \mathrm{HEPES}, 8 \mathrm{NaCl}, 4$ magnesium ATP, 0.3 sodium GTP, and 0.5 EGTA. Tetrodotoxin ( $1 \mu \mathrm{M}$, Tocris Bioscience) and bicuculline (10 $\mu \mathrm{M}$, Tocris Bioscience) were added into the extracellular solution during mEPSC recordings. For mIPSC recordings, tetrodotoxin (1 $\mu \mathrm{M}$, Tocris Bioscience) and NBQX (10 $\mu \mathrm{M}$, Tocris Bioscience) were added. Synaptic currents were analyzed using a customized macro in Igor Pro (WaveMetrics).

\section{Results}

Selected SALM family proteins induce presynaptic differentiation

To determine whether the SALM proteins regulate synapse formation, we performed coculture (or mixed-culture) assays, in which synaptic adhesion molecules of interest are expressed in nonneural cells and are tested for their abilities to induce presynaptic or postsynaptic differentiation in contacting axons or dendrites of cocultured neurons (Scheiffele et al., 2000; Biederer and Scheiffele, 2007). Of the five SALM family members expressed in HEK293T cells, SALM3 and SALM5, but not SALM1, SALM2, and SALM4, selectively induced presynaptic differentiation, defined by the clustering of synapsin I, a presynaptic marker, in contacting axons of cocultured hippocampal neurons (DIV 9-12) (Fig. $1 A, B$ ). Surface expression levels of SALM1, SALM2, and SALM3 were comparable, suggesting that selective presynaptic differentiation by SALM3 is not caused by its higher surface expression. Similar surface expression levels were also observed for SALM4 and SALM5, whose expression levels were higher rel- 
ative to SALM1, SALM2, and SALM3 (supplemental Fig. S1, available at www. jneurosci.org as supplemental material).

To determine whether the extracellular domains of SALM3 and SALM5 are sufficient for presynaptic induction, we generated SALM constructs (SALMs-Ecto) using the pDisplay vector in which the extracellular domains of interest are flanked by HA and Myc epitope tags and are fused to the transmembrane domain of an unrelated membrane protein (plateletderived growth factor receptor) that lacks a cytoplasmic region. Coculture experiments with HEK293T cells transfected with the SALM-Ecto constructs demonstrated that SALM3 and SALM5, but not SALM1, SALM2, and SALM4, selectively induce presynaptic differentiation, as shown by synapsin I clustering (Fig. $1 C, D)$. SALM3 and SALM5 also induced presynaptic differentiation in younger neurons (DIV 5-8) (supplemental Fig. S2, available at www.jneurosci.org as supplemental material). These results further demonstrate that SALM3 and SALM5 are capable of inducing presynaptic differentiation and that the extracellular domains of SALM3 and SALM5 are sufficient for presynaptic induction. These results suggest that selected members of SALM fam-

ily, SALM3 and SALM5, have the activity to induce presynaptic differentiation.

\section{SALM3 and SALM5 induce excitatory and inhibitory} presynaptic differentiation and neurotransmitter release

We further tested whether SALM3 and SALM5 induce clustering of other presynaptic proteins, specifically the presynaptic vesicle protein synaptophysin and the presynaptic active zone protein Piccolo. SALM3-Ecto and SALM5-Ecto expressed in HEK293T cells induced robust presynaptic clustering of synaptophysin and Piccolo (Fig. 2A-C). By contrast, SALM3 and SALM5 did not induce clustering of PSD-95 and gephyrin (an inhibitory postsynaptic protein) in contacting dendrites (supplemental Fig. S3, available at www.jneurosci.org as supplemental material). In addition, postsynaptic receptors (NMDA receptors and GABA receptors) were not clustered by SALM3 or SALM5 (supplemental Fig. S4, available at www.jneurosci.org as supplemental material). This suggests that the presynaptic protein clustering observed on SALM3/ 5 -expressing cells do not represent presynaptic protein clusters at normal interneuronal synapses.

We next sought to determine whether SALM3 and SALM5 induce excitatory and/or inhibitory presynaptic differentiation. SALM3 and SALM5, induced the clustering of vGlut1, an excitatory presynaptic marker, in contacting axons of cocultured neurons (Fig. $2 D, F$ ). In addition, clustering of VGAT, an inhibitory presynaptic marker, was induced by SALM3 and SALM5 (Fig. $2 E, F)$. These results suggest that SALM3 and SALM5 induce excitatory and inhibitory presynaptic differentiation in contacting axons.

To determine whether the presynaptic structures induced by SALM3 and SALM5 are functional (i.e., release neurotransmitters), we used an assay in which functional neurotransmitter re-
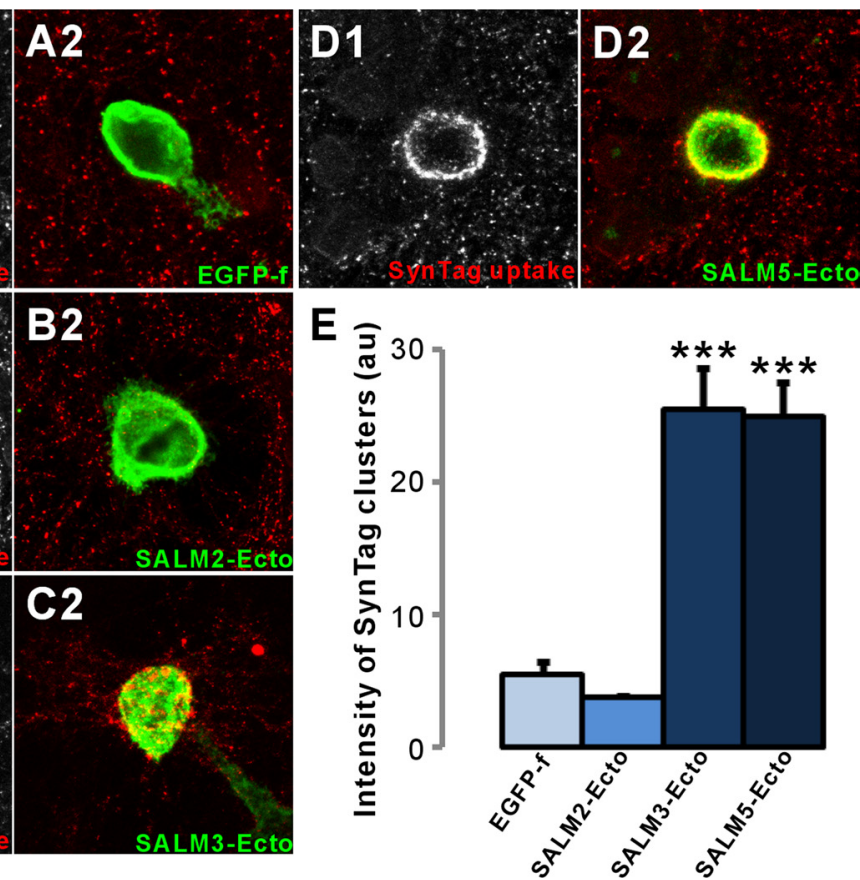

gmin lumenal domain antibodies in contacting axons of cocultured neurons. A-D, HEK293T cells were transfected with SALM2-Ecto, SALM3-Ecto, SALM5-Ecto, or EGFP-f (control), were cocultured with rat (DIV 9-12), followed by the incubation of the live neurons with synaptotagmin I (SynTag) lumenal domain antidies to tag functional presynaptic nerve terminals and double staining for SynTag $(\boldsymbol{A 1}, \boldsymbol{B 1}, \mathbf{C 1}$, and D1) and EGFP (A2)/HA (for SALMs-

lease is visualized in live neurons by incubating with antibodies directed against the lumenal domain of the synaptic vesicle protein synaptotagmin 1 (Kraszewski et al., 1995). Indeed, SALM3 and SALM5, but not SALM2, induced the uptake of synaptotagmin 1 lumenal domain antibodies in contacting axons (Fig. 3). These results suggest that SALM3 and SALM5 induce functional presynaptic differentiation in contacting axons.

\section{Expression patterns and protein interactions of SALM3 and SALM5}

The mRNA expression patterns of all five SALMs have previously been determined by Northern and in situ hybridization analyses (Ko et al., 2006; Morimura et al., 2006); however, expression patterns of SALM3 and SALM5 proteins have not been characterized in detail (Seabold et al., 2008). To this end, we generated SALM3- and SALM5-specific polyclonal antibodies (supplemental Fig. S5A, available at www.jneurosci.org as supplemental material). Immunoblot analyses with these antibodies revealed that SALM3 and SALM5 proteins are predominantly detected in the brain, with lower levels of SALM5 expressed in the testis (Fig. $4 A$ ). The molecular masses of SALM3 and SALM5 in the brain were $\sim 80$ and $100 \mathrm{kDa}$, respectively. These masses are similar to those of SALM3 and SALM5 expressed in heterologous cells (supplemental Fig. S5B, available at www.jneurosci.org as supplemental material) and are slightly higher than the predicted molecular masses of SALM3 $(67.3 \mathrm{kDa})$ and SALM5 $(79.4 \mathrm{kDa})$, likely due to glycosylation. Expression of SALM3 and SALM5 gradually increased in the first 3 weeks of postnatal rat brain development (Fig. $4 B$ ), during the time when active synaptogenesis occurs. SALM3 and SALM5 proteins were predominantly detected in the synaptic fractions of rat brain subcellular fractions including P2 (crude synaptosome) and LP1 (synaptic mem- 
A

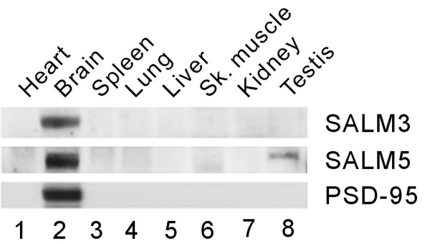

B

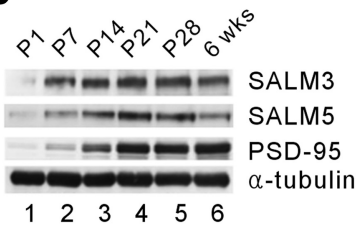

C

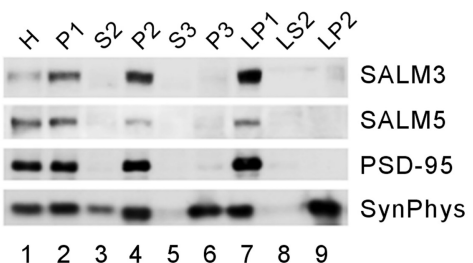

D

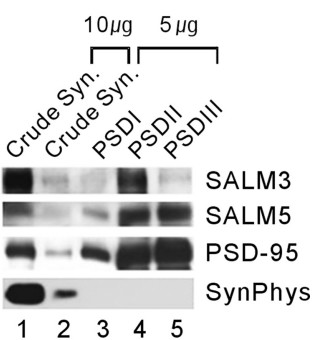

E

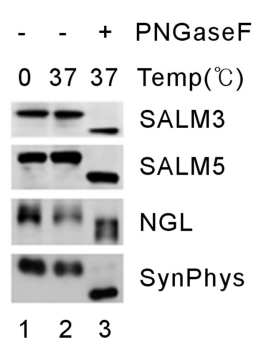

F

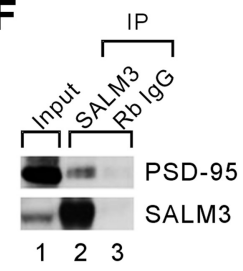

G

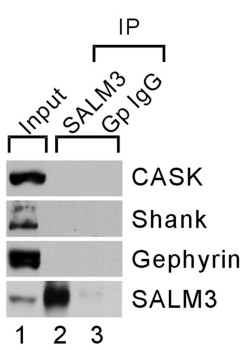

H

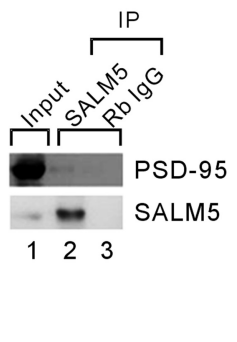

I

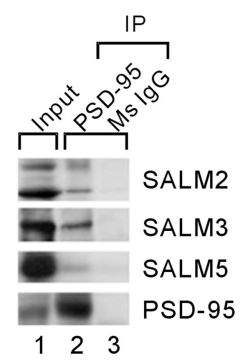

Figure 4. Expression patterns and distinct protein interactions of SALM3 and SALM5. A, SALM3 and SALM5 proteins are mainly expressed in the brain. Whole tissue homogenates were immunoblotted with SALM3 (1828) and SALM5 (1911) antibodies. Note that a small amount of SALM5 expression is detected in the testis. PSD-95 was visualized for comparison. Sk., skeletal. $\boldsymbol{B}$, Expression levels of SALM3 and SALM5 proteins are gradually increased during postnatal rat brain development. P, Postnatal day; wks, weeks. $\alpha$-Tubulin was visualized for normalization. C, Preferential Distribution of SALM3 and SALM5 proteins to synaptic subcellular fractions of adult rat brain. Note that SALM3 and SALM5 proteins are mainly detected in synaptic fractions, including P2 and LP1. PSD-95 and synaptophysin (SynPhys) were probed for comparison. H, Homogenates; P1, crude nuclear fraction; P2, crude synaptosomes; S2, supernatant after P2 precipitation; S3, cytosol; P3, light membranes; LP1, synaptosomal membranes; LS2, synaptosomal cytosol; LP2, synaptic vesicle-enriched fraction. D, Enrichment of SALM3 and SALM5 proteins in postsynaptic (PSD) fractions of adult rat brain (6 weeks). PSD I, II, and III represent fractions extracted with Triton X-100 once (PSD I), twice (PSD II), or with Triton X-100 followed by Sarkosyl (PSD III). Note the strong PSD enrichment of SALM5 up to PSD III, similar to PSD-95. E, N-Glycosylation of SALM3 and SALM5. The crude synaptosomal fraction of adult rat brain was subjected to PNGase $F$ digestion, followed by immunoblot analysis. F, G, SALM3 forms a complex with PSD-95 in brain. Detergent lysates of the crude synaptosomal fraction (P2) from adult rat brain (6 weeks) were immunoprecipitated with SALM3 antibodies, followed by immunoblotting with the indicated antibodies. H, SALM5 forms a weak complex with PSD-95. P2 detergent lysates were immunoprecipitated with SALM5 (1907) antibodies, followed by immunoblotting with SALM5 (1911) and PSD-95 antibodies. I, PSD-95 forms a complex strongly with SALM2 and SALM3, but weakly with SALM5. P2 detergent lysates were immunoprecipitated with PSD-95 antibodies, followed by immunoblotting.
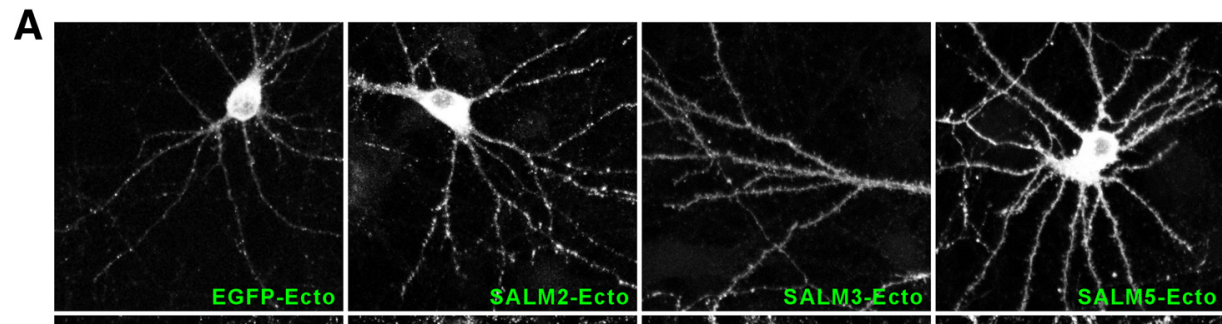

B
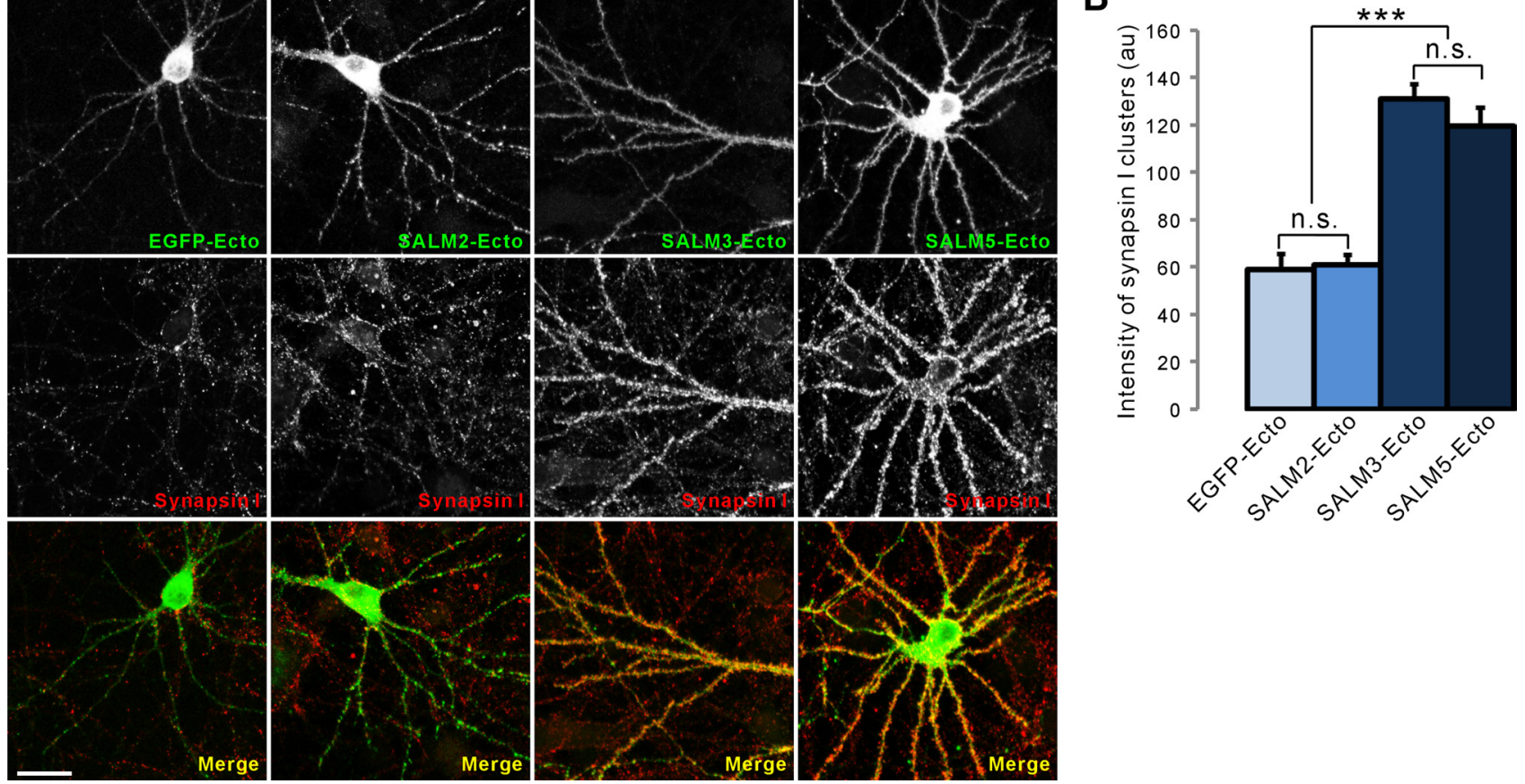

Figure 5. Overexpression of SALM3 and SALM5 in cultured neurons increases the amount of presynaptic contacts. $A$, Cultured hippocampal neurons were transfected with EGFP-Ecto (EGFP in pDisplay vector, negative control), SALM2-Ecto (negative control), SALM3-Ecto, or SALM5-Ecto at DIV 14 and immunostained for synapsin I at DIV 17. Scale bar, $30 \mu \mathrm{m}$. $\boldsymbol{B}$, Quantification of the results from $A$. Mean \pm SEM (EGFP-Ecto, $59.0 \pm 6.7, n=18 ;$ SALM2-Ecto, $61.0 \pm 4.7, n=22 ;$ SALM3-Ecto, $131.2 \pm 6.2, n=35 ;$ SALM5-Ecto, $119.7 \pm 7.9, n=21 ;$ n.s., not significant, ${ }^{* * *} p<0.001$, ANOVA, Tukey's test). 

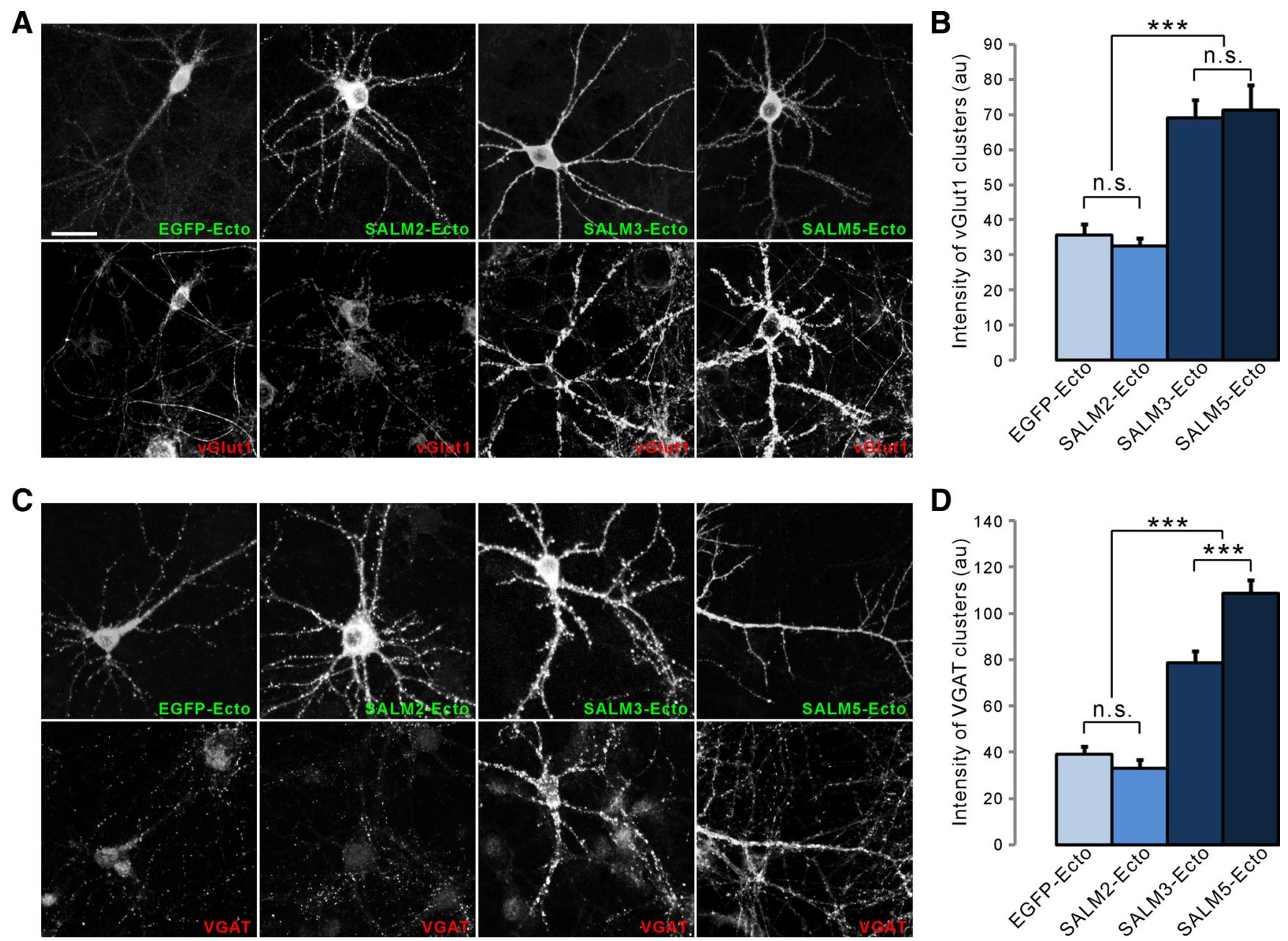

Figure 6. Overexpression of SALM3 and SALM5 in cultured neurons increases the amount of excitatory and inhibitory presynaptic contacts. $A, C$, Cultured hippocampal neurons were transfected with EGFP-Ecto, SALM2-Ecto, SALM3-Ecto, or SALM5-Ecto at DIV 14 and immunostained for vGlut1 $(\boldsymbol{A})$ and VGAT (C) at DIV 17. Scale bar, $30 \mu \mathrm{m}$. $\boldsymbol{B}$, Quantification of results from $A$. Mean \pm SEM (EGFP-Ecto, $35.75 \pm 2.9, n=25 ;$ SALM2-Ecto, $32.6 \pm 2.2, n=42 ;$ SALM3-Ecto, $69.1 \pm 5.1, n=37 ;$ SALM5-Ecto, $71.3 \pm 7.1, n=18 ;$ n.S., not significant, ${ }^{* * * *} p<$ 0.001, ANOVA, Tukey's test). D, Quantification of the results from C. Mean \pm SEM (EGFP-Ecto, 39.2 $\pm 3.4, n=27 ;$ SALM2-Ecto, $32.9 \pm 3.6, n=25 ;$ SALM3-Ecto, $78.7 \pm 5.2, n=31$; SALM5-Ecto, $108.5 \pm 5.9, n=23 ; n . s .=$ not significant, ${ }^{* * *} p<0.001$, ANOVA, Tukey's test).

brane), similar to the distribution patterns of PSD-95 (Fig. 4C). SALM3 and SALM5 were enriched in postsynaptic density (PSD) fractions, with SALM5 being enriched to an extent similar to PSD-95 (Fig. 4D). Digestion with PNGaseF reduced the molecular masses of SALM3 and SALM5, indicating that these proteins are modified by $\mathrm{N}$-glycosylation (Fig. $4 E$ ).

SALM1, SALM2, and SALM3 differ from SALM4 and SALM5 in that the former possess C-terminal PDZ-binding motifs, which bind the PDZ domains of PSD-95 (Ko et al., 2006; Morimura et al., 2006; Wang et al., 2006). Therefore, we investigated whether SALM3 and SALM5 proteins form complexes with PSD-95 by in vivo coimmunoprecipitation experiments. SALM3 formed a complex with PSD-95 but not with other postsynaptic proteins CASK, Shank, and gephryin (Fig. $4 F, G$ ), while SALM5 only weakly coprecipitated with PSD-95 (Fig. 4H). In coimmunoprecipitation assays in a reverse orientation, PSD-95 brought down a significant amount of SALM3, but only a small amount of SALM5, relative to the amounts of these proteins in the input lanes (Fig. 4I). The association of SALM2 with PSD-95, used as a positive control, is consistent with the previous results (Ko et al., 2006). These results suggest that SALM 3 and SALM5 proteins are enriched in synaptic fractions and associate with PSD-95 with different affinities.

\section{Overexpression of SALM3 or SALM5 in cultured neurons increases presynaptic contacts}

We next tested whether overexpression of SALM3 or SALM5 in neurons could regulate presynaptic differentiation in contacting axons, as it did in nonneural cells. Transfection of cultured hippocampal neurons with constructs containing the extracellular domain of SALM3 or SALM5 (SALM3-Ecto and SALM5-Ecto) markedly increased the amount of presynaptic contacts, as measured by the intensity of synapsin I clusters on dendrites (Fig. 5). In contrast, overexpression of SALM2-Ecto, or EGFP-Ecto, had no effect on presynaptic contacts.

SALM3 or SALM5 expressed in nonneural cells induced both excitatory and inhibitory presynaptic differentiation in contacting axons (Fig. 2). Similarly, SALM3 or SALM5 expressed in hippocampal neurons increased the amount of excitatory and inhibitory presynaptic contacts, as measured by the intensity of vGlut1 and VGAT clusters, respectively, on dendrites (Fig. 6).

We also attempted to overexpress full-length SALM3 and SALM5 (not extracellular domain-only constructs) in cultured 


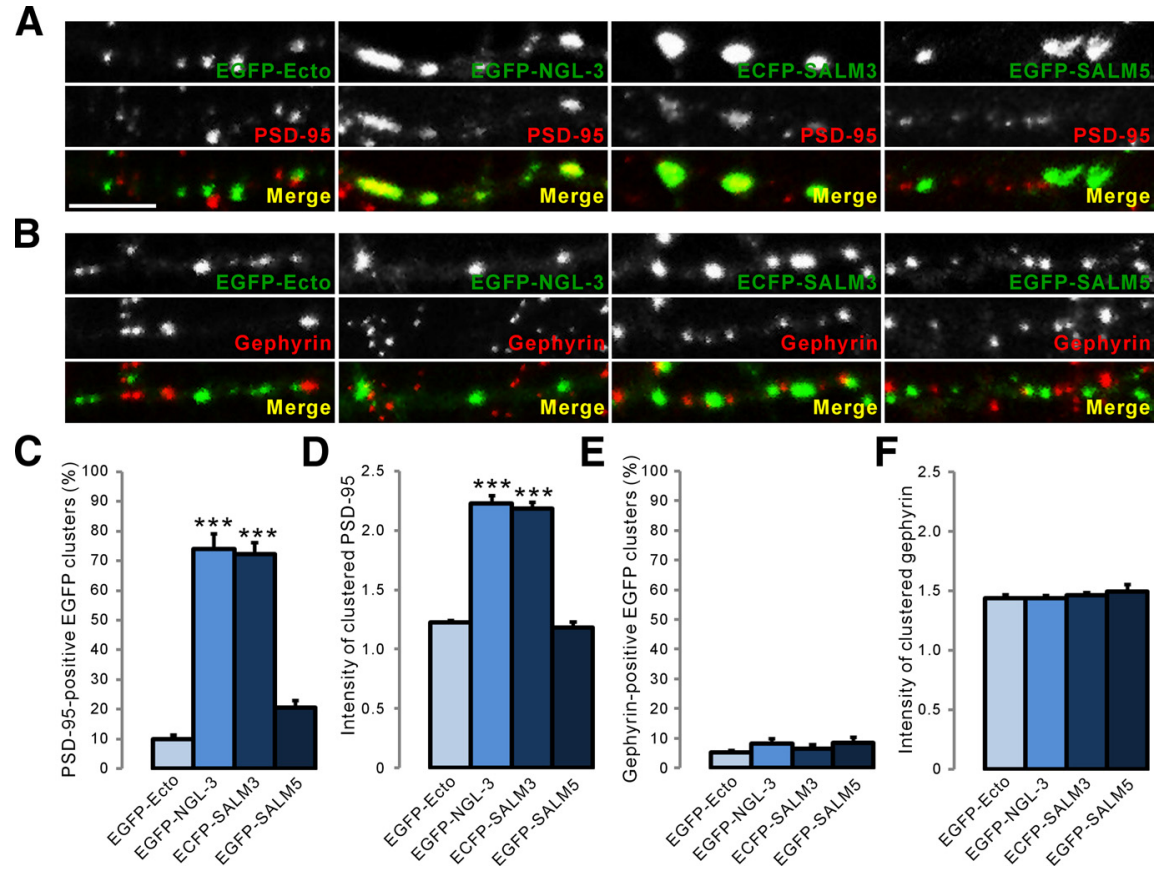

Figure 7. Aggregation of SALM3, but not SALM5, on dendritic surfaces induces clustering of PSD-95, but not gephyrin. $\boldsymbol{A}, \boldsymbol{B}$, Cultured hippocampal neurons were transfected with EGFP-Ecto (EGFP in pDisplay, negative control), EGFP-NGL-3 (Nterminally EGFP-tagged full-length NGL-3, positive control), ECFP-SALM3 (N-terminally ECFP-tagged full-length SALM3), or EGFPSALM5 (N-terminally EGFP-tagged full-length SALM5) at DIV 14. Transfected neurons were incubated with preclustered EGFP antibody for $24 \mathrm{~h}$ and immunostained for PSD-95 $(\boldsymbol{A})$ and gephyrin $(\boldsymbol{B})$ at DIV 16. Scale bar, $10 \mu \mathrm{m}$. $\boldsymbol{C}$, Percentage of PSD-95positive EGFP clusters. Mean \pm SEM (EGFP-Ecto, $9.9 \pm 1.5, n=16$; EGFP-NGL-3, $73.9 \pm 5.3, n=18$; ECFP-SALM3, 70.7 \pm 4.0 $n=19 ;$ EGFP-SALM5, $23.1 \pm 2.5, n=14 ;{ }^{* * *} p<0.001$, ANOVA, Tukey's test). $\boldsymbol{D}$, Intensity of PSD-95 clusters normalized to those in adjacent dendrites. Mean \pm SEM (EGFP-Ecto, $1.22 \pm 0.02, n=438 ;$ EGFP-NGL-3, $2.23 \pm 0.06, n=262 ;$ ECFP-SALM3, $2.18 \pm 0.06, n=252 ;$ EGFP-SALM5, $1.18 \pm 0.04, n=134 ;{ }^{* *} p<0.001$, ANOVA, Tukey's test). , Percentage of gephyrinpositive EGFP clusters. Mean \pm SEM (EGFP-Ecto, $5.08 \pm 0.79, n=11$; EGFP-NGL-3, $8.16 \pm 1.69, n=21$; ECFP-SALM3, $6.52 \pm$ $1.39, n=25$; EGFP-SALM5, $8.42 \pm 1.92, n=15) . \boldsymbol{F}$, Intensity of gephyrin clusters normalized to those in adjacent dendrites Mean \pm SEM (EGFP-Ect0, $1.44 \pm 0.03, n=471 ;$ EGFP-NGL-3, $1.44 \pm 0.03, n=488$; ECFP-SALM3, $1.46 \pm 0.02, n=671$ EGFP-SALM5, $1.50 \pm 0.06, n=321)$.

neurons, but found that this caused significant negative effects on neuronal morphologies including the shrinkage/removal of dendritic spines (data not shown). This was likely due to mislocalization of SALM3- or SALM5-associated postsynaptic proteins (i.e., PSD-95) by overexpressed and widely distributed SALM3/ SALM5 proteins, an effect that is reminiscent of the dominantnegative effects of mislocalized SALM2 and neuroligin 2 on synapse number and function (Graf et al., 2004; Ko et al., 2006).

\section{Aggregation of SALM3 but not SALM5 on dendritic surfaces induces PSD-95 clustering}

We next tested whether aggregation of SALM3 or SALM5 on the surface of dendrites is sufficient to induce secondary clustering of other postsynaptic proteins. To this end, we expressed N-terminally ECFP/EGFP-tagged SALM3 or SALM5 in cultured neurons and then incubated these neurons with preclustered anti-EGFP antibodies, thus causing artificial aggregations of ECFP-SALM3 or EGFP-SALM5 proteins on dendritic surfaces. Aggregation of ECFP-SALM3, but not EGFP-Ecto, caused secondary clustering of PSD-95 at sites of SALM3 aggregation, as determined by measurements of the extent of PSD-95 colocalization at ECFP-SALM3 aggregates and the intensity of PSD-95 clusters (Fig. $7 A, C, D$ ). The extent of PSD-95 clustering induced by SALM3 was similar to that induced by NGL-3, a positive control adhesion molecule with synaptogenic activity (Woo et al., 2009b). In contrast, SALM5 aggregation did not induce PSD-95 clustering (Fig. $7 A, C, D$ ), likely due to the lack of a PSD-95-binding $C$ terminus in SALM5. Clustering of gephyrin, an inhibitory postsynaptic protein, was not induced by aggregation of either SALM3 or SALM5 (Fig. $7 B, E, F$ ). These results indicate that aggregation of SALM3, but not SALM5, on dendritic surfaces is sufficient to induce the clustering of PSD-95, but not gephyrin. This also suggests that, despite the fact that SALM3 and SALM5 similarly induce both excitatory and inhibitory presynaptic differentiation, they are distinct from one another with respect to clustering of postsynaptic proteins.

\section{Knockdown of SALM5 reduces the number and function of excitatory and inhibitory synapses}

We tested whether reduced expression of SALM3 or SALM5 affects synapse number or function using an RNA interference approach. To this end, we attempted to generate knockdown constructs for SALM3 and SALM5. We were able to generate a SALM5 shRNA construct (sh-SALM5) that reduced SALM5 expression in heterologous cells by $80 \%$ (supplemental Fig. S5, available at www.jneurosci.org as supplemental material). However, a sh-SALM3 could not be generated despite repeated attempts.

SALM5 knockdown in cultured hippocampal neurons (DIV 10-14 or 15) significantly reduced the number of both excitatory and inhibitory synapses compared with neurons transfected with empty shRNA vector (sh-vec), as assessed by vGlut1-positive PSD-95and VGAT-positive gephyrin clusters, respectively (Fig. $8 A-D$ ). The effect of SALM5 knockdown on synapse number was slightly greater on excitatory than inhibitory synapses. In contrast, a mutant form of sh-SALM5 that is not active for SALM5 ( sh-SALM5*; supplemental Fig. S6, available at www.jneurosci. org as supplemental material) had no effect on excitatory or inhibitory synapses relative to sh-vec. In addition, coexpression of a sh-SALM5-resistant rescue SALM5 expression construct (SALM5 res; supplemental Fig. S6, available at www.jneurosci. org as supplemental material) with sh-SALM5 rescued shSALM5-induced reductions in excitatory and inhibitory synapses (Fig. 8A-D), further indicating that sh-SALM5 specifically reduces SALM5 expression.

In addition to reducing the number of synapses, SALM5 knockdown suppressed synaptic functions, inhibiting both spontaneous excitatory and inhibitory synaptic transmissions. The frequencies of both miniature EPSCs (mEPSCs) and miniature IPSCs (mIPSCs) were significantly reduced by SALM5 knockdown (Fig. $8 E-G$ ). Notably, mEPSCs were reduced to a much greater extent than were mIPSCs. The amplitudes of mEPSCs and mIPSCs were also reduced by SALM5 knockdown (Fig. 8 E, F, H). These results collectively suggest that SALM5 knockdown negatively regulates the number and function of excitatory and inhibitory synapses, and that SALM5 has a greater influence on excitatory synapses than on inhibitory synapses. 
A sh-vec

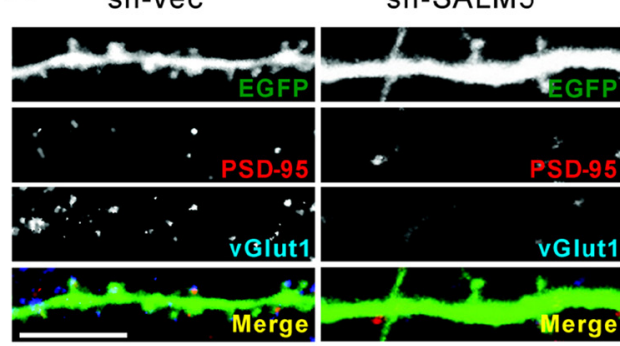

sh-SALM5*

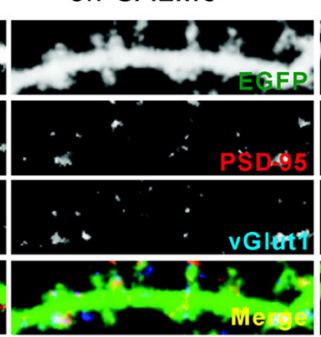

sh-SALM5

+ SALM5 res

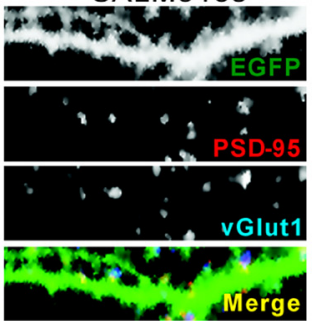

C

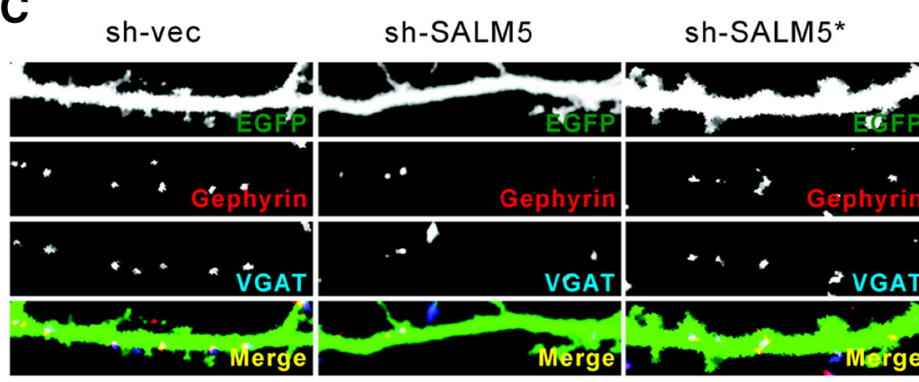

sh-SALM5 + SALM5 res

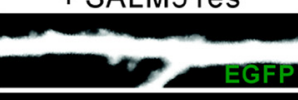

E

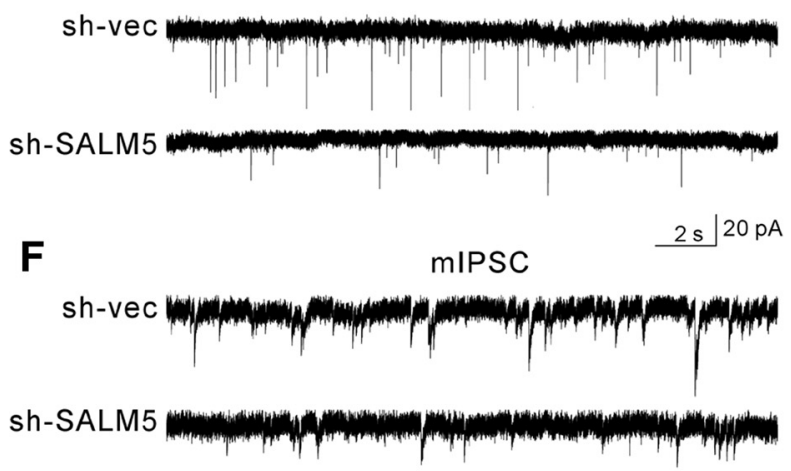

G

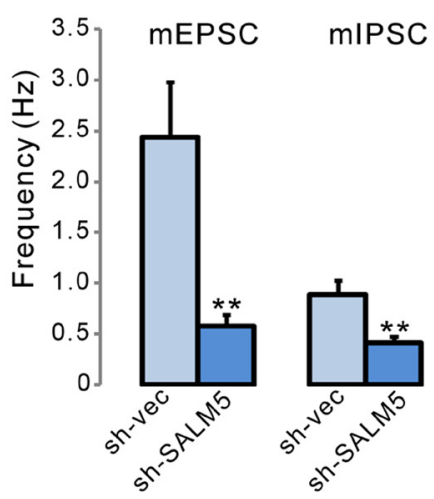

B

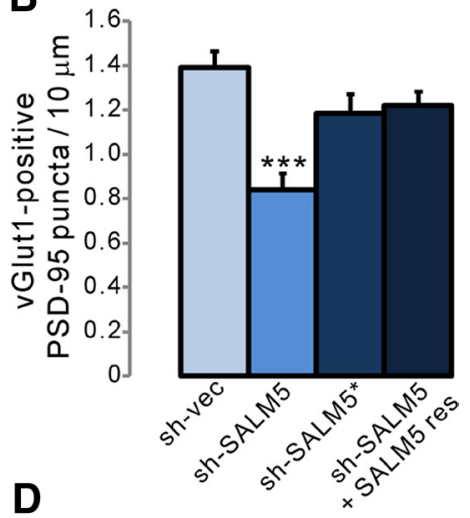

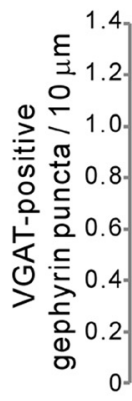

H

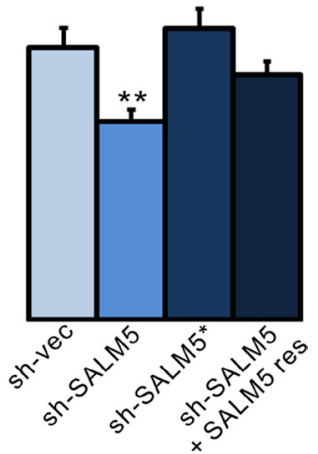

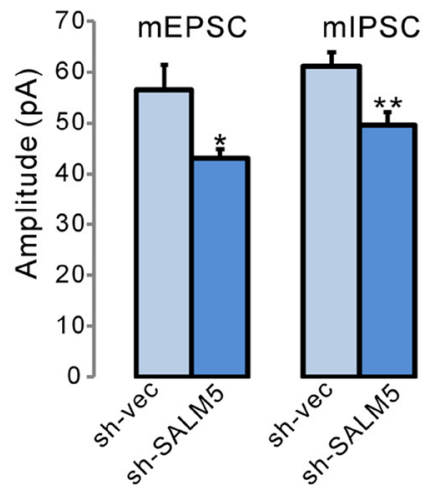

Figure 8. Knockdown of SALM5 decreases the number and function of both excitatory and inhibitory synapses. A, C, SALM 5 knockdown reduces the number of excitatory and inhibitory synapses. Cultured hippocampal neurons were transfected with sh-vec (empty shRNA vector), sh-SALM5, sh-SALM5* (a point-mutated sh-SALM5 that is not active for SALM5), or sh-SALM5 + SALM5 res (an sh-SALM5-resistant rescue SALM5 expression construct) at DIV 10 and immunostained for excitatory synaptic markers (PSD-95 and vGlut1), or inhibitory synaptic markers (gephyrin and VGAT), at DIV 14. Bar, $10 \mu \mathrm{m}$. B, Quantification of the number of excitatory synapses. Mean \pm SEM (sh-vec, $1.39 \pm 0.08, n=44$; sh-SALM5, $0.84 \pm 0.08, n=36 ;$ sh-SALM5*, $1.19 \pm 0.09, n=35$; sh-SALM5 + SALM5 res, $1.22 \pm 0.06, n=55 ; * * * p<0.001$, ANOVA, Tukey's test). D, Quantification of the number of inhibitory synapses. Mean \pm SEM (sh-vec, $1.06 \pm 0.08, n=48 ;$; sh-SALM5, $0.77 \pm 0.05, n=50$; sh-SALM5* $1.14 \pm 0.08, n=35$; Rescue, $0.96 \pm 0.05, n=46 ; * * 00.01$, ANOVA, Tukey's test). $\boldsymbol{E}, \boldsymbol{F}$, Knockdown of SALM5 decreases both the frequency and amplitude of $\mathrm{mEPSCs}$ and $\mathrm{mIPSCS}$. Representative traces for $\mathrm{mEPSCS}(\boldsymbol{E})$ and $\mathrm{mIPSCS}(\boldsymbol{F})$. G, Quantitative analysis of the frequencies of $\mathrm{mEPSC}$ and $\mathrm{mIPSC}$. Mean \pm SEM ( $\mathrm{mEPSC}$; $5 \mathrm{~h}$-vec, $2.43 \pm 0.55, n=$ 14; sh-SALM5, $0.58 \pm 0.11, n=14 ; \mathrm{mIPSC}$; sh-vec, $0.89 \pm 0.13, n=21$; sh-SALM5, $0.41 \pm 0.06, n=21$; ** $p<0.01$, Student's $t$ test). $\boldsymbol{H}$, Quantitative analysis of the amplitudes of mEPS(s and mIPSCs. Mean \pm SEM (mEPSCs; sh-vec, $56.5 \pm 5.1, n=14$; sh-SALM5, $43.1 \pm 1.9, n=14 ; \mathrm{mIPSCs}$; sh-vec, $61.2 \pm 2.8, n=21$; sh-SALM5, $49.6 \pm 2.6, n=21 ;{ }^{*} p<0.05$, ${ }^{* *} p<0.01$, Student's $t$ test).

\section{Discussion}

Involvement of a subset of SALM family members in presynaptic differentiation

Since the discovery of the SALM family of "adhesion-like" molecules, there has been much uncertainty concerning the abilities of these proteins to function as adhesion molecules. Our results demonstrate that SALM3 and SALM5 induce presynaptic differentiation through their extracellular domains, which likely interact with specific presynaptic adhesion molecules. A recent study demonstrated that SALM4 and SALM5 can mediate transcellular adhesion in a homophilic manner (Seabold et al., 2008). Taken together with our results, this strongly supports the notion that SALMs can act as adhesion molecules.

Our observation that SALM3 and SALM5, but not other SALMs, induce presynaptic differentiation indicates that different members of the SALM family have distinct functions. This notion stems in part from the observation that the cytoplasmic regions of SALMs differ in length, amino acid sequence, and binding proteins (Ko et al., 2006; Morimura et al., 2006; Wang et al., 2006). For instance, a PDZ-binding motif involved in PSD-95 
interaction is present in SALM1, SALM2 and SALM3, but not in SALM4 or SALM5 (Ko et al., 2006; Morimura et al., 2006; Wang et al., 2006). Unlike the cytoplasmic regions of SALMs, the extracellular domains of SALMs share as much as $50-60 \%$ amino acid sequence identity, indicating that they might have shared functions. However, our results clearly indicate that the extracellular domains of SALM3 and SALM5 are functionally distinct from those of other SALMs, at least with regard to the ability to induce presynaptic differentiation in contacting axons.

SALM3 and SALM5 expressed in nonneural cells induced both excitatory and inhibitory presynaptic differentiation in contacting axons. Essentially the same results were obtained when SALM3 and SALM5 were expressed in cultured neurons. These functional characteristics of SALM3 and SALM5 are reminiscent of those reported for neuroligin 1 and neuroligin 2, which induce both excitatory and inhibitory presynaptic differentiation (Scheiffele et al., 2000; Graf et al., 2004). However, endogenous neuroligin 1 and neuroligin 2 distribute to and preferentially regulate the formation and function of excitatory and inhibitory synapses, respectively (Craig and Kang, 2007; Südhof, 2008). We could not specifically determine the localization of endogenous SALM3 and SALM5 at excitatory and/or inhibitory synapses due to the lack of antibodies suitable for immunohistochemistry analysis. Notably, however, SALM5 knockdown caused reductions in the number and function of both excitatory and inhibitory synapses. This aspect of SALM5 function thus seems to distinguish SALM5 from neuroligins, which act specifically on either excitatory or inhibitory synapses, although further studies on SALM5 are required to confirm this. In addition, LRRTM2 and NGL-3, which contain LRRs similar to SALMs, have been implicated mainly in the regulation of excitatory synapse formation (de Wit et al., 2009; Ko et al., 2009; Linhoff et al., 2009; Woo et al., 2009b; Kwon et al., 2010).

\section{Differences in synapse formation by SALM3 and SALM5}

Our data indicate that SALM3 and SALM5 share a common functional characteristic: the ability to promote excitatory and inhibitory presynaptic differentiation. However, SALM3 and SALM5 apparently differ in other aspects of synapse formation. In particular, SALM3 and SALM5 promote different patterns of postsynaptic protein clustering; SALM3 induced the clustering of PSD-95 but not gephyrin, whereas SALM5 did not induce the clustering of either protein. The absence of PSD-95-clustering activity in SALM5 may be attributable to the lack of a C-terminal PDZ-binding motif in SALM5 (Ko et al., 2006; Morimura et al., 2006; Wang et al., 2006). These results suggest the possibility that SALM5 is a synaptogenic molecule that acts in a unidirectional manner in the trans-synaptic axis, capable of inducing presynaptic differentiation, but not postsynaptic clustering. However, the possibility that SALM5 regulates clustering of some other postsynaptic proteins cannot be ruled out.

In conclusion, our study identifies a novel synaptogenic function of selected members of the SALM family. SALM3 and SALM5 regulate excitatory and inhibitory synapse formation through similar presynaptic effects but distinct postsynaptic effects. A useful focus for future studies would be an investigation of the detailed mechanisms underlying SALM3- and SALM5dependent regulation of excitatory and inhibitory synapse formation, including a search for specific presynaptic ligands for SALM3 and SALM5.

\section{References}

Akins MR, Biederer T (2006) Cell-cell interactions in synaptogenesis. Curr Opin Neurobiol 16:83-89.
Biederer T, Scheiffele P (2007) Mixed-culture assays for analyzing neuronal synapse formation. Nat Protoc 2:670-676.

Brose N (2009) Synaptogenic proteins and synaptic organizers: "many hands make light work." Neuron 61:650-652.

Choi J, Ko J, Racz B, Burette A, Lee JR, Kim S, Na M, Lee HW, Kim K, Weinberg RJ, Kim E (2005) Regulation of dendritic spine morphogenesis by insulin receptor substrate 53, a downstream effector of Racl and Cdc42 small GTPases. J Neurosci 25:869-879.

Craig AM, Kang Y (2007) Neurexin-neuroligin signaling in synapse development. Curr Opin Neurobiol 17:43-52.

Dalva MB, McClelland AC, Kayser MS (2007) Cell adhesion molecules: signalling functions at the synapse. Nat Rev Neurosci 8:206-220.

Dean C, Dresbach T (2006) Neuroligins and neurexins: linking cell adhesion, synapse formation and cognitive function. Trends Neurosci 29:21-29.

de Wit J, Sylwestrak E, O'Sullivan ML, Otto S, Tiglio K, Savas JN, Yates JR 3rd, Comoletti D, Taylor P, Ghosh A (2009) LRRTM2 interacts with Neurexin 1 and regulates excitatory synapse formation. Neuron 64:799-806.

Giagtzoglou N, Ly CV, Bellen HJ (2009) Cell adhesion, the backbone of the synapse: "vertebrate" and "invertebrate" perspectives. Cold Spring Harb Perspect Biol 1:a003079.

Graf ER, Zhang X, Jin SX, Linhoff MW, Craig AM (2004) Neurexins induce differentiation of GABA and glutamate postsynaptic specializations via neuroligins. Cell 119:1013-1026.

Han K, Kim E (2008) Synaptic adhesion molecules and PSD-95. Prog Neurobiol 84:263-283.

Kim MH, Choi J, Yang J, Chung W, Kim JH, Paik SK, Kim K, Han S, Won H, Bae YS, Cho SH, Seo J, Bae YC, Choi SY, Kim E (2009) Enhanced NMDA receptor-mediated synaptic transmission, enhanced long-term potentiation, and impaired learning and memory in mice lacking IRSp53. J Neurosci 29:1586-1595.

Kim S, Ko J, Shin H, Lee JR, Lim C, Han JH, Altrock WD, Garner CC, Gundelfinger ED, Premont RT, Kaang BK, Kim E (2003) The GIT family of proteins forms multimers and associates with the presynaptic cytomatrix protein Piccolo. J Biol Chem 278:6291-6300.

Kim S, Burette A, Chung HS, Kwon SK, Woo J, Lee HW, Kim K, Kim H, Weinberg RJ, Kim E (2006) NGL family PSD-95-interacting adhesion molecules regulate excitatory synapse formation. Nat Neurosci 9:1294-1301.

Ko J, Kim E (2007) Leucine-rich repeat proteins of synapses. J Neurosci Res 85:2824-2832.

Ko J, Kim S, Valtschanoff JG, Shin H, Lee JR, Sheng M, Premont RT, Weinberg RJ, Kim E (2003) Interaction between liprin-alpha and GIT1 is required for AMPA receptor targeting. J Neurosci 23:1667-1677.

Ko J, Kim S, Chung HS, Kim K, Han K, Kim H, Jun H, Kaang BK, Kim E (2006) SALM synaptic cell adhesion-like molecules regulate the differentiation of excitatory synapses. Neuron 50:233-245.

Ko J, Fuccillo MV, Malenka RC, Südhof TC (2009) LRRTM2 functions as a neurexin ligand in promoting excitatory synapse formation. Neuron 64:791-798.

Kraszewski K, Mundigl O, Daniell L, Verderio C, Matteoli M, De Camilli P (1995) Synaptic vesicle dynamics in living cultured hippocampal neurons visualized with CY3-conjugated antibodies directed against the lumenal domain of synaptotagmin. J Neurosci 15:4328-4342.

Kwon SK, Woo J, Kim SY, Kim H, Kim E (2010) Trans-synaptic adhesions between netrin-G ligand-3 (NGL-3) and receptor tyrosine phosphatases LAR, PTP $\{$ delta $\}$, and PTP $\{$ sigma $\}$ via specific domains regulate excitatory synapse formation. J Biol Chem. Advance online publication. Retrieved Feb. 6, 2010. doi:10.1074/jbc.M109.061127.

Levinson JN, El-Husseini A (2005) Building excitatory and inhibitory synapses: balancing neuroligin partnerships. Neuron 48:171-174.

Li Z, Sheng M (2003) Some assembly required: the development of neuronal synapses. Nat Rev Mol Cell Biol 4:833-841.

Linhoff MW, Laurén J, Cassidy RM, Dobie FA, Takahashi H, Nygaard HB, Airaksinen MS, Strittmatter SM, Craig AM (2009) An unbiased expression screen for synaptogenic proteins identifies the LRRTM protein family as synaptic organizers. Neuron 61:734-749.

Morimura N, Inoue T, Katayama K, Aruga J (2006) Comparative analysis of structure, expression and PSD95-binding capacity of Lrfn, a novel family of neuronal transmembrane proteins. Gene 380:72-83. 
Scheiffele P (2003) Cell-cell signaling during synapse formation in the CNS. Annu Rev Neurosci 26:485-508.

Scheiffele P, Fan J, Choih J, Fetter R, Serafini T (2000) Neuroligin expressed in nonneuronal cells triggers presynaptic development in contacting axons. Cell 101:657-669.

Seabold GK, Wang PY, Chang K, Wang CY, Wang YX, Petralia RS, Wenthold RJ (2008) The SALM family of adhesion-like molecules forms heteromeric and homomeric complexes. J Biol Chem 283: $8395-8405$.

Südhof TC (2008) Neuroligins and neurexins link synaptic function to cognitive disease. Nature 455:903-911.

Togashi H, Sakisaka T, Takai Y (2009) Cell adhesion molecules in the central nervous system. Cell Adh Migr 3:29-35.

Wang CY, Chang K, Petralia RS, Wang YX, Seabold GK, Wenthold RJ (2006)
A novel family of adhesion-like molecules that interacts with the NMDA receptor. J Neurosci 26:2174-2183.

Wang PY, Seabold GK, Wenthold RJ (2008) Synaptic adhesion-like molecules (SALMs) promote neurite outgrowth. Mol Cell Neurosci 39:83-94.

Washbourne P, Dityatev A, Scheiffele P, Biederer T, Weiner JA, Christopherson KS, El-Husseini A (2004) Cell adhesion molecules in synapse formation. J Neurosci 24:9244-9249.

Woo J, Kwon SK, Kim E (2009a) The NGL family of leucine-rich repeatcontaining synaptic adhesion molecules. Mol Cell Neurosci 42:1-10.

Woo J, Kwon SK, Choi S, Kim S, Lee JR, Dunah AW, Sheng M, Kim E (2009b) Trans-synaptic adhesion between NGL-3 and LAR regulates the formation of excitatory synapses. Nat Neurosci 12:428-437.

Yamagata M, Sanes JR, Weiner JA (2003) Synaptic adhesion molecules. Curr Opin Cell Biol 15:621-632. 